07.2

\title{
Влияние режимов работы на отклик сенсоров аммиака на основе пленок диоксида олова
}

\author{
(C) А.В. Цымбалов, В.М. Калыгина, Н.К. Максимова, Е.В. Черников \\ Национальный исследовательский Томский государственный университет, Томск, Россия \\ E-mail: zoldmine@gmail.com
}

Поступило в Редакцию 4 декабря 2019г.

В окончательной редакции 22 февраля 2020г.

Принято к публикации 25 фревраля 2020 г.

\begin{abstract}
Изучено влияние режимов работы на величину отклика сенсоров аммиака на основе пленок диоксида олова. Образцы получены в результате высокочастотного магнетронного распыления мишени $\mathrm{SnO}_{2}: \mathrm{Sb}$ на сапфировые подложки с предварительно нанесенными Pt-электродами и нагревателем. Варьирование длительности цикла нагрева и снижение температуры в цикле охлаждения позволяют повысить величину отклика на один-два порядка. Полученные результаты объясняются изменением плотности химически адсорбированного кислорода на поверхности пленки $\mathrm{SnO}_{2}: \mathrm{Sb}$ в зависимости от температурного режима.
\end{abstract}

Ключевые слова: диоксид олова, аммиак, тонкие пленки, магнетронное распыление, режим термоциклирования.

DOI: 10.21883/PJTF.2020.10.49426.18141

Спрос на датчики аммиака определяется необходимостью их использования в различных отраслях промышленности, сельского хозяйства, медицине, производстве взрывчатых веществ и т.д. Например, аммиак используется для изготовления азотных удобрений, которые широко применяются в сельском хозяйстве. Датчики аммиака могут использоваться для диагностики различных заболеваний пищеварительного тракта по определению концентрации $\mathrm{NH}_{3}$ в выдыхаемой газовой смеси [1]. Из-за ежедневного выброса промышленных предприятий растет содержание вредных веществ в воздухе, в том числе диоксида азота $\left(\mathrm{NH}_{3}\right)$. Избыток аммиака в атмосфере оказывает негативное влияние на здоровье человека, и это часто приводит к хроническим заболеваниям. В связи с отмеченным выше существует необходимость мониторинга окружающей среды.

К разрабатываемым датчикам предъявляется ряд требований, таких как малые времена отклика и восстановления, высокий отклик, стабильность работы при выбранных условиях, селективность, низкая потребляемая мощность, что крайне важно для работы устройств в автономном режиме. Модификация датчиков за счет использования катализаторов приводит к тому, что они становятся селективными к определенным газам [2-6]. Катализаторы на поверхности пленки не только увеличивают селективность, но и повышают отклик сенсоров. Палладий, платина, иридий являются наиболее подходящими катализаторами аммиака [7].

Ранее было показано, что при работе сенсоров в режиме термоциклирования удается получить более высокий отклик [8] при более низкой потребляемой мощности. Режим термоциклирования - это последовательное чередование импульсов нагрева и охлаждения. Во время каждого цикла задаются определенная температура и длительность цикла [8].

Целью настоящей работы является установление параметров циклов нагрева и охлаждения, обеспечивающих высокий отклик сенсоров аммиака при меньшей потребляемой мощности.

Тонкая пленка диоксида олова (150-200 nm) была получена методом высокочастотного магнетронного распыления мишени $\mathrm{SnO}_{2}: \mathrm{Sb}$ на ненагретую сапфировую подложку в газовой смеси кислород/аргон (60 vol.\% кислорода). В качестве катализатора на поверхность пленок наносилась тем же способом мелкодисперсная платина. Платиновые электрические контакты и нагреватель на поверхности сапфировой подложки формировались

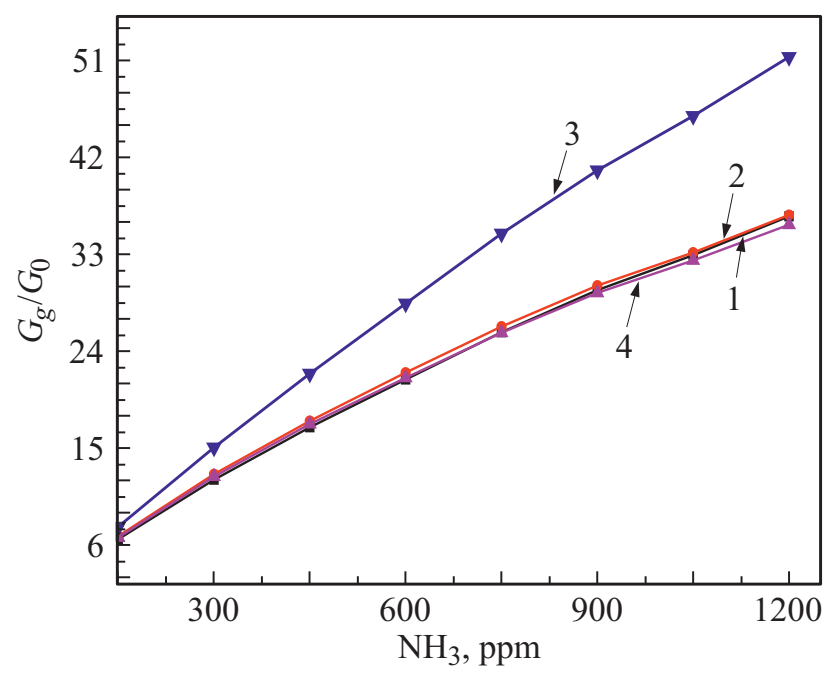

Рис. 1. Зависимость отклика сенсоров от концентрации аммиака в режиме постоянного нагрева. Цифры около кривых соответствуют номерам сенсоров. 

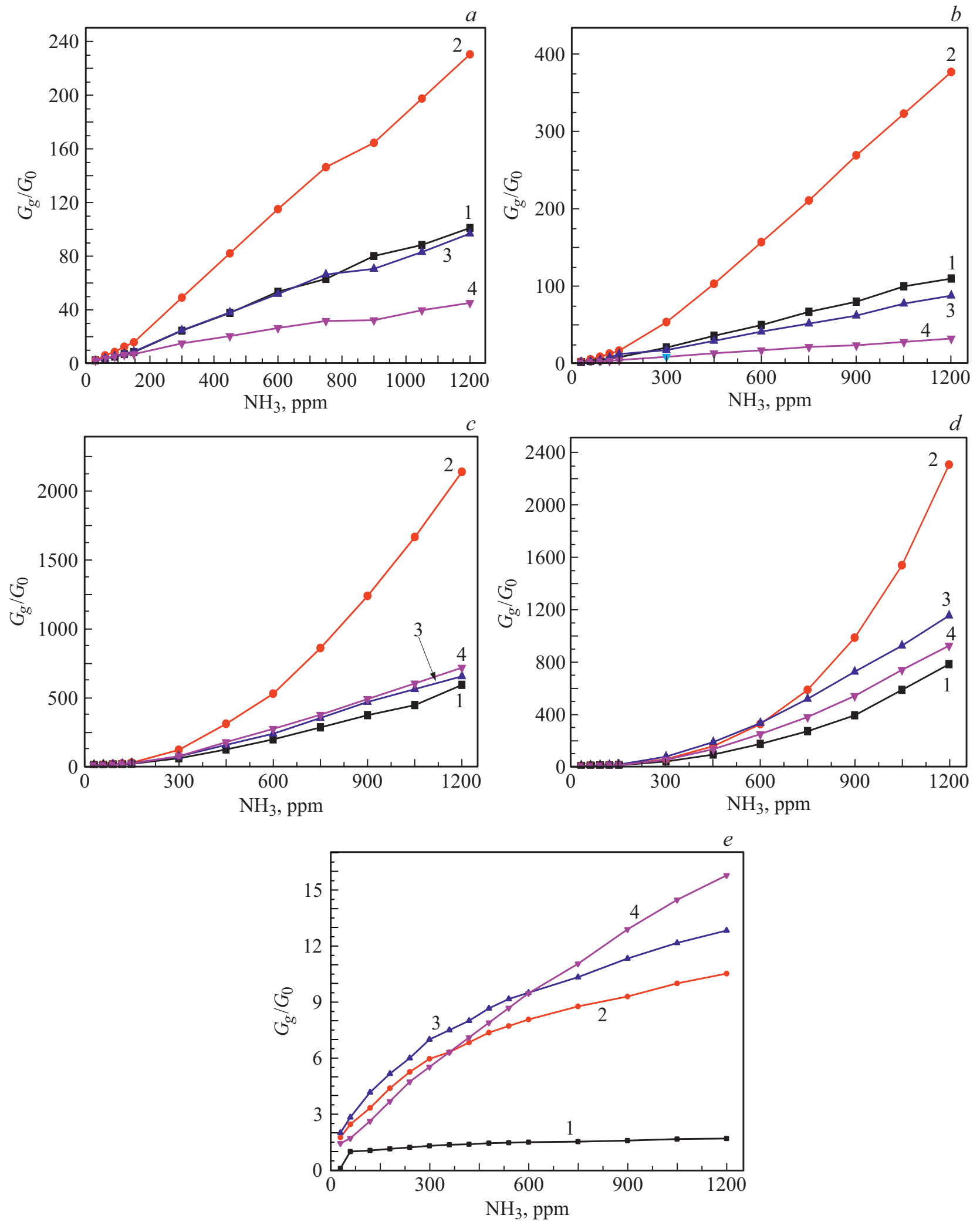

Рис. 2. Зависимость отклика сенсоров от концентрации аммиака в режиме термоциклирования (цикл охлаждения): $400^{\circ} \mathrm{C}(8 \mathrm{~s})-200^{\circ} \mathrm{C}(5 \mathrm{~s})(a), 400^{\circ} \mathrm{C}(8 \mathrm{~s})-100^{\circ} \mathrm{C}(5 \mathrm{~s})(b), 400^{\circ} \mathrm{C}(6 \mathrm{~s})-100^{\circ} \mathrm{C}(5 \mathrm{~s})(c), 400^{\circ} \mathrm{C}(4 \mathrm{~s})-50^{\circ} \mathrm{C}(5 \mathrm{~s})(d), 350^{\circ} \mathrm{C}(8 \mathrm{~s})-50^{\circ} \mathrm{C}$ $(5 \mathrm{~s})(e)$. Обозначение кривых то же, что на рис. 1. 
с помощью фотолитографии до получения оксидной пленки. Для повышения стехиометрии пленка диоксида олова отжигалась в камере в воздушной среде в течение $24 \mathrm{~h}$ при температуре $425^{\circ} \mathrm{C}$. После отжига сапфировая пластина с нанесенными пленкой $\mathrm{SnO}_{2}$, электродами и нагревателем разрезалась на отдельные образцы размером $1.4 \times 1.4 \mathrm{~mm}$. Изготовление датчиков заканчивалось распайкой Pt-контактов и нагревателя на кристаллдержатель с помощью золотой проволоки диаметром $50 \mu \mathrm{m}$ и размещением их в корпуса.

Все измерения проводились в изолированной стеклянной камере объемом один литр с использованием специальной разработанной измерительной установки и устройства, обрабатывающего и передающего сигнал на компьютер. Данное оборудование позволяет измерять изменения сопротивления (либо проводимости) со временем в зависимости от концентрации анализируемого газа, определять влажность в измерительной камере, контролировать температуру нагрева (или охлаждения) одновременно для четырех сенсоров. Газовая смесь $\mathrm{N}_{2} / \mathrm{NH}_{3}(96.96 / 3.04$ vol.\%) подавалась в систему с использованием шприца-дозатора. Размещенное внутри камеры устройство обеспечивало равномерное распределение анализируемого газа по всей камере и позволяло поддерживать постоянной во время проведения измерений относительную влажность (в наших экспериментах $\mathrm{RH}=32-34 \%$ ). В работе рассматриваются четыре газовых сенсора из одной партии (далее образцы № 1-4).

Отклик сенсоров $G_{g} / G_{0}$ определялся как отношение проводимости образца в газовой смеси $\mathrm{NH}_{3} /$ воздух $\left(G_{g}\right)$ к проводимости в воздушной среде $\left(G_{0}\right)$. Измерения отклика сенсоров осуществлялись в режимах непрерывного нагрева и термоциклирования. В режиме постоянного нагрева отклик сенсоров измерялся при $T_{w}=340^{\circ} \mathrm{C}$. Значения $T_{w}$ определялись по предварительно измеренной температурной зависимости $G_{g} / G_{0}$ при фиксированной концентрации газа.

При использовании термоциклирования температура в цикле нагрева $T_{h}$ поддерживалась равной $350-400^{\circ} \mathrm{C}$, длительность импульсов $t_{h}$ варьировалась в интервале $8-4 \mathrm{~s}$. Температура цикла охлаждения $\left(T_{c}\right)$ изменялась от 200 до $50^{\circ} \mathrm{C}$ при постоянной длительности $t_{c}=5 \mathrm{~s}$.

На рис. 1 показаны концентрационные зависимости отклика сенсоров в режиме постоянного нагрева. Отношение $G_{g} / G_{0}$ не превышает 40-50 при концентрации аммиака $1200 \mathrm{ppm}$. Отклик в режиме термоциклирования в цикле нагрева имеет примерно такие же значения, если $T_{h}=400^{\circ} \mathrm{C}$.

На рис. 2 показаны зависимости откликов сенсоров от концентрации аммиака также при использовании режима термоциклирования, но отношение $G_{g} / G_{0}$ рассчитывалось для цикла охлаждения при нескольких значениях $T_{c}$ и длительностях цикла нагрева $t_{h}$. Согласно представленным данным, при измерении в цикле охлаждения отклик сенсоров увеличился в 3-4 раза при использовании $T_{h}=400^{\circ} \mathrm{C}\left(t_{h}=8 \mathrm{~s}\right)$ и $T_{c}=200^{\circ} \mathrm{C}\left(t_{c}=5 \mathrm{~s}\right)$ по сравнению с полученным в режиме постоянного нагрева (рис. $2, a)$. При снижении $T_{c}$ до $100^{\circ} \mathrm{C}$ отклик увеличился еще в 2 раза (рис. 2,b). Дальнейшее повышение чувствительности сенсоров было получено после снижения длительности цикла нагрева до $6 \mathrm{~s}$, и отношение $G_{g} / G_{0}$ возросло до 2200 для образца № 2 и до 600 для образцов № 1, 3 и 4 (рис. 2,c). Для всех сенсоров отклик увеличился, когда длительность цикла нагрева была уменьшена до $4 \mathrm{~s}$ при $T_{c}=50^{\circ} \mathrm{C}$ (рис. $2, d$ ).

Отклик сенсоров объясняется реакцией молекул аммиака с кислородом, химически адсорбированным на поверхности диоксида олова по реакции

$$
2 \mathrm{NH}_{3}+3 \mathrm{O}^{-} \longleftrightarrow \mathrm{N}_{2}+3 \mathrm{H}_{2} \mathrm{O}+3 e^{-}
$$

где $e^{-}$- электрон, который поступает в зону проводимости полупроводника и обеспечивает рост проводимости сенсора $G_{g}$. Считается, что на поверхности пленки в присутствии платины происходят каталитические реакции [9], в результате которых происходит разложение молекулы аммиака на азот и атомарный водород. Атомарный водород и кислород на поверхности вступают в реакцию, образуя молекулы воды. Таким образом уменьшаются плотность хемосорбированного кислорода и, как следствие, ширина области пространственного заряда кристаллитов оксидной пленки. В свою очередь количество отрицательно заряженных ионов кислорода $\mathrm{O}^{-}$на поверхности полупроводниковой пленки регулируется соотношением температур в циклах нагрева и охлаждения и их продолжительностью. Рост отклика сенсора при снижении температуры $T_{c}$ объясняется тем, что атомарный кислород, сформированный в цикле нагрева, не успевает ассоциироваться в молекулярный при низких температурах [8].

Если температура нагрева недостаточно высокая (например, $350^{\circ} \mathrm{C}$ ), чтобы обеспечить необходимую плотность ионов $\mathrm{O}_{a}^{-}$, то отклик сенсоров резко падает (рис. 2,e). На основании данных, представленных выше, можно сделать вывод, что наиболее оптимальным является следующий режим работы сенсора: $400^{\circ} \mathrm{C}(4 \mathrm{~s})-50^{\circ} \mathrm{C}(5 \mathrm{~s})$. В этих условиях резко увеличивается чувствительность сенсоров по сравнению с чувствительностью в режиме постоянного нагрева при меньшей потребляемой мощности.

\section{Конфликт интересов}

Авторы заявляют, что у них нет конфликта интересов.

\section{Список литературы}

[1] Timmer B., Olthuis W., van den Berg A. // Sensors Actuators. B. 2005. V. 107. P. 666-677. https://doi.org/10.1016/.snb.2004.11.054

[2] Xiong Y., Xu W., Ding D., Lu W., Zhu L., Zhu Z., Wang Y., Xue $Q$. // J. Hazard. Mater. 2018. V. 341. P. 159-167. https://doi.org/10.1016/j.jhazmat.2017.07.060 
[3] Marikutsa A., Krivetskiya V., Yashina L., Rumyantseva M., Konstantinova E., Ponzoni A., Comini E., Abakumov A., Gaskov A. // Sensors Actuators B. 2012. V. 175. P. 186-183. https://doi.org/10.1016/j.snb.2012.03.003

[4] Wagh M.S., Jain G.H., Patil D.R., Patil S.A., Patil L.A. // Sensors Actuators B. 2006. V. 115. P. 128-133. https://doi.org/10.1016/j.snb.2005.08.030

[5] Xu C.N., Miura N., Ishida Y., Matsuda K., Yamazoe N. // Sensors Actuators B. 2000. V. 65. P. 163-165. https://doi.org/10.1016/S0925-4005(99)00413-X

[6] Marikutsa A., Rumyantseva M., Gaskov A. // Chemosensors. 2015. V. 3. P. 241-252. DOI: 10.3390/chemosensors3040241

[7] Звягинцев О.Е. // ЖПХ. 1959. Т. XXXII. В. 9. С. 1889-1899.

[8] Максимова Н.К., Севастьянов Е.Ю., Серегейченко Н.В., Черников E.B. Полупроводниковые тонкопленочные газовые сенсоры. Томск: Изд-во НТЛ, 2016. 164 с.

[9] Зятьков И.И., Максимов А.И., Мошников В.А. Сенсоры на основе полевых транзисторов. СПб.: Изд-во СПбГЭТУ „ЛЭТИ“, 2002. 55 c. 